\title{
DIFFERENCES INFLUENCE OF AQUATIC THERAPY AND NEURO DEVELOPMENTAL TREATMENT ON THE MOTOR FUNCTIONAL DEVELOPMENT ABILITY OF CHILDREN WITH CEREBRAL PALSY
}

\author{
Bambang Trisnowiyanto ${ }^{1}$, M. Mudatsir Syatibi ${ }^{2}$ \\ 1,2 JURUSAN FISIOTERAPI DI POLTEKKES KEMENKES SURAKARTA
}

Email: btrisnowiyanto@gmail.com

DOI : https://doi.org/10.35451/jkf.v2i2.413

\begin{abstract}
Cerebral Palsy (CP) is a motor disability disorder that most commonly occurs in children so that sufferers are unable to perform functional activities independently and need special service. Aquatic therapy and neuro developmental are interventions of physical therapy to help improve the motor functional development ability. The purpose of research is to find out the difference between aquatic therapy and neuro developmental treatment on the motor functional development ability of children with cerebral palsy. The type of research is quasi-experimental research with a pretest and posttest design. The subject of the research is the cerebral palsy community in Yogyakarta, namely Wahana Keluarga Cerebral Palsy (WKCP). The mann-whitney test use to test the hypothesis statistically. The results are difference in influence from aquatic therapy and neuro developmental treatment on the motor functional development ability of children with cerebral palsy, especially in the dimension of sitting, crawling and kneeling, standing, walking, running and jumping, and not for dimension of supine and prone. The conclusion is aquatic exercise is more influential on the motor functional development ability of children with cerebral palsy compared to neuro developmental treatment.
\end{abstract}

Keywords: aquatic therapy, neuro developmental treatment, functional motor development ability, cerebral palsy.

\section{PENDAhUluan}

Cerebral Palsy (CP) merupakan gangguan disabilitas motorik yang paling umum terjadi pada anak-anak dengan prevalensi 2-3 per 1000 kelahiran hidup (Stavsky et al., 2017). $50 \%$ kasus termasuk ringan yaitu penderita dapat mengurus dirinya sendiri, dan $10 \%$ tergolong berat yaitu penderita membutuhkan pelayanan khusus. 35\% disertai kejang dan 50\% mengalami gangguan bicara, dengan rata-rata $70 \%$ tipe spastik, $10-20 \%$ tipe atetotik, 5-10\% ataksia, dan sisanya bertipe campuran (Selina, Priambodo, \& Sakundarno, 2013) (Graham et al., 2016) (MacLennan, Thompson, \& Gecz, 2015).
CP merupakan kumpulan gangguan motorik akibat kerusakan otak yang terjadi sebelum, selama atau setelah lahir yang dapat disebabkan oleh banyak faktor seperti, kongenital, genetik, inflasi, infeksi dan keracunan pada saat masa kehamilan, trauma dan gangguan metabolik. Kerusakan otak anak, mempengaruhi sistem motorik dan sebagai hasilnya anak memiliki koordinasi yang buruk, keseimbangan yang kurang baik atau pola gerakan yang abnormal atau gabungan dari karakteristik tersebut (Morgan \& McGinley, 2018) (Arshad, Imran, Munir, Akram, \& Hameed, 2018) (Shira Sender, 2019).

Lesi sistem saraf pusat (SSP) pada anak dengan $\mathrm{CP}$ dapat menyebabkan 
gangguan sensorik dan motorik yang akan semakin memburuk seiring berjalannya waktu. CP terjadi pada setiap 2 per 1000 dan hingga 2,5 per 1000 kelahiran hidup. Tantangan utama untuk CP adalah disfungsi pada motorik kasar. Selain itu, tingkat keparahannya adalah keterbatasan fungsi motorik kasar dengan kecacatan fisik umum sangat bervariasi. Masalah motorik CP timbul secara fundamental dari disfungsi SSP, yang mengganggu perkembangan kontrol postural normal terhadap gravitasi serta akan menghambat perkembangan motorik normal (Labaf, Shamsoddini, Taghi Hollisaz, Sobhani, \& Shakibaee, 2015) (Graham et al., 2016).

Posisi, duduk, transisi dari duduk ke berdiri, berjalan dengan atau tanpa alat bantu dan alat bantu, penggunaan kursi roda dan transfer, adalah area yang dikerjakan oleh ahli fisioterapi. Latihan mengacu pada kegiatan terstruktur yang direncanakan yang melibatkan gerakan berulang tulang otot yang menghasilkan pengeluaran energi dan berusaha untuk meningkatkan atau mempertahankan level kebugaran fisik di atas intensitas kegiatan hidup sehari-hari. Beberapa jenis terapi latihan digunakan untuk meningkatkan kemampuan motorik anak diantaranya adalah passive stretching, manual stretching, static weight-bearing, strength training aim, functional exercises, aquatic therapy, bobath concept, training programs, dan electrical stimulation (Kerem, 2011) (Marret, Vanhulle, \& Laquerriere, 2013).

Pada anak-anak dengan CP perlu dilakukan tindakan untuk menghindari tonus dan postur otot yang abnormal, untuk merawat otot dan deformitas sendi, dan untuk mengurangi gangguan pada motorik dan sensorik. Terapi akuatik dan neurodevelopmental merupakan terapi yang dapat diimplementasikan untuk mengurangi dan mencegah kecacatan lebih lanjut pada anak dengan CP (Labaf et al., 2015) (Vitrikas, Dalton, \& Breish, 2020) (McIntyre et al., 2013).

Air menyediakan lingkungan yang diinginkan untuk anak-anak dan remaja dengan CP. Hasil dari, aktivitas fisik akuatik lebih melindungi integritas sendi dari aktivitas berbasis darat. Penelitian telah melaporkan hal itu melakukan keterampilan motorik di dalam air dapat berpotensi meningkat kepercayaan diri dan mengarah pada resistensi kurang untuk mencoba tugas-tugas sulit dibandingkan dengan pelatihan darat (Gorter \& Currie, 2011) (Dimitrijević et al., 2012).

Beberapa penelitian telah menunjukkan potensi program terapi akuatik pada pediatri, secara signifikan memberi manfaat bagi penderita CP. Terapi akuatik memiliki efek fisiologis yang dapat diklasifikasikan menjadi 2, yaitu efek termal dan mekanis. Efek mekanis meliputi hidrostatik dan hidrodinamik. Efek mekanis dari terapi akuatik meliputi daya apung, tekanan hidrostatik, dan gaya hidrodinamik. Daya apung mengurangi efek gravitasi dan memungkinkan anak-anak dengan cerebral palsy melakukan aktivitas yang tidak dapat mereka lakukan di darat. Tekanan hidrostatik dapat membantu dalam pelatihan otot, dan gaya hidrodinamik memfasilitasi pelatihan keseimbangan dan postur. Efek termal dapat meningkatkan elastisitas jaringan lunak, mengurangi rasa sakit, dan mengurangi kelenturan pada penderita CP (Lai et al., 2015) (Chiquoine, McCauley, \& Van Dyke, 2018).

Olahraga di air mengurangi pengaruh gravitasi, meningkatkan dukungan postural, mengurangi pemuatan dan dampak gabungan, dan meningkatkan kekuatan aerobik dan otot untuk penderita CP. Berdasarkan penjabaran tersebut dapat dinyatakan bahwa terapi di air lebih bermanfaat daripada terapi di darat. Kelemahan otot, keselarasan sendi yang buruk, dan kontraktur otot pada penderita $\mathrm{CP}$ dapat menyebabkan masalah dalam keterlibatan dan kepatuhan pada terapi konvensional berbasis darat. Terapi akuatik melindungi integritas sendi lebih dari sekadar latihan berbasis darat dan telah terbukti bermanfaat di meningkatkan fungsi motorik kasar, mengurangi kelenturan, meningkatkan daya tahan kardiorespirasi dan 
kapasitas vital, serta meningkatkan kemampuan pola jalan pada penderita CP (Lai et al., 2015) (Roostaei, Baharlouei, Azadi, \& Fragala-Pinkham, 2017).

Menurut International Bobath Instructors Training Association (IBITA), bobath konsep atau neuro developmental treatment (NDT) adalah sebuah pendekatan problem-solving yang dapat diaplikasikan kepada semua usia dan segala derajat keterbatasan fisik dan fungsi untuk pemeriksaan dan penanganan bagi individu dengan gangguan fungsi, gerak, dan kontrol postural oleh karena lesi sistem saraf pusat (Gorter \& Currie, 2011) (Dimitrijević et al., 2012).

Pendekatan NDT untuk pengembangan saraf pada $\mathrm{CP}$ merupakan pendekatan yang paling luas dan secara klinis dapat diterima untuk menargetkan pada SSP dan neuromuskuler sistem. Lesi spesifik di SSP itu 'mengajarkan' otak untuk meningkatkan keterampilan kinerja motorik dan mencapai 'fungsi sedekat mungkin'. Tujuan utama dari pendekatan ini adalah untuk memperbaiki postural abnormal dan untuk memfasilitasi pola geraka normal sehingga mencapai ketrampilan kinerja yang lebih baik (Labaf et al., 2015) .

Tingkat kemandirian pada anak dengan cerebral palsy perlu diperiksa oleh tenaga kesehatan khususnya fisioterapi. Dalam hal ini, digunakan alat ukur berupa Gross Motor Function Measure (GMFM). GMFM merupakan suatu jenis pengukuran klinis yang dapat dilakukan pada anak dengan CP. Terdiri dari 88 item pemeriksaan mencakup aktifitas pada posisi berbaring dan berguling (17 item), duduk (20 item), merangkak dan kneeling (14 item), berdiri (13 item), berjalan (12 item), berlari dan melompat (12 item). Terdapat 4 skor penilaian yaitu $0,1,2$ dan 3 yang masing-masing memiliki arti $0=$ tidak memiliki inisiatif, $1=$ inisiatif, $2=$ dapat melakukan sebagian, 3 = dapat melakukan seluruh gerakan (Harvey, 2017) (Kenyon, 2014).

Berdasarkan uraian sebelumnya, dapat disusun rumusan masalah dalam penelitian ini adalah sebagai berikut: (1) apakah latihan akuatik berpengaruh terhadap perkembangan kemampuan motorik fungsional anak dengan CP?, (2) apakah latihan NDT berpengaruh terhadap perkembangan kemampuan motorik fungsional anak dengan CP?, dan (3) apakah ada perbedaan antara latihan akuatik dan NDT terhadap perkembangan motorik fungsional anak dengan $\mathrm{CP}$ ?

Adapun tujuan dalam penelitian ini adalah: (1) untuk mengetahui pengaruh latihan akuatik berpengaruh terhadap perkembangan kemampuan motorik fungsional anak dengan $\mathrm{CP}$, (2) untuk mengetahui pengaruh latihan NDT berpengaruh terhadap perkembangan kemampuan motorik fungsional anak dengan $\mathrm{CP}$, dan (3) untuk mengetahui perbedaan antara latihan akuatik dan NDT terhadap perkembangan motorik fungsional anak dengan $\mathrm{CP}$.

\section{METODE PENELITIAN}

Jenis penelitian yang dilakukan adalah penelitian eksperimen semu dengan rancangan pretest dan posttest design. Penelitian dilakukan pada komunitas CP di Yogyakarta, yaitu Wahana Keluarga Cerebral Palsy (WKCP). Penelitian dilakukan selama 8 minggu mulai bulan Mei sampai dengan bulan Juni tahun 2016.

Populasi dalam penelitian ini adalah seluruh anggota komunitas CP di WKCP. Sampel yang digunakan dalam penelitian ini adala sejumlah 20 subjek yang dipilih melalui kriteria inklusi dan eksklusi.

Kriteria inklusi dalam penelitian ini adalah (1) pasien CP jenis kelamin lakilaki maupun perempuan, berusia di bawah 12 tahun, (2) pasien bersedia mengikuti program terapi selama kurang lebih enam minggu, (3) tidak mengalami gangguan sensibilitas, (4) nilai GMFM minimal $50 \%$.

Kriteria eksklusi dalam penelitian ini adalah (1) pasien terdapat kelainan sendi misalnya club foot atau CTEV, (2) pasin memiliki gangguan kognitif yang mengganggu jalannya penelitian. 
Kriteria drop out dalam penelitian ini adalah (1) pasien tidak menyelesaikan latihan secara penuh, (2) pasien tidak hadir pada saat evaluasi akhir, (3) pasien tidak mengikuti latihan lebih dari lima kali.

Variabel dalam penelitian ini adalah variabel bebas adalah terapi akuatik dan neuro developmental treatment (NDT) dan variabel terikatnya adalah kemampuan motorik fungsional.

Instrumen penelitian yang digunakan dalam penelitian ini adalah blanko pemeriksaan kemampuan fungsional dasar GMFM. Terdiri dari 88 item pemeriksaan, aktifitas pada posisi berbaring dan berguling (17 item), duduk (20 item), merangkak dan kneeling (14 item), berdiri (13 item), berjalan (12 item), berlari dan melompat (12 item). Penilaian GMFM ada 4 skor yaitu 0, 1, 2 dan 3 yang masing-masing mempunyai arti $0=$ tidak memiliki inisiatif, $1=$ inisiatif, $2=$ sebagian dilengkapi, 3 = dilengkapi.

Setelah data pemeriksaan telah di kumpulkan sampai dengan akhir penelitian maka data akan dianalisa dahulu. Pertama akan ditentukan skala pengukuran variabel, untuk penelitian ini skala pengukurannya adalah numerik dengan jenis penelitiannyaa dalah komparatif, selanjutnya data pada penelitian ini akan bersifat berpasangan 2 kelompok. Jika data normal, maka uji beda dalam kelompok digunakan paired $t$-test dan untuk antar kelompok digunakan independent $t$ - test. Namun jika data tidak normal, maka untuk uji beda dalam kelompok digunakan Wilcoxon test dan untuk antar kelompok digunakan MannWhitney test.

\section{HASIL DAN PEMBAHASAN}

Penelitian ini dilakukan pada bulan Mei sampai dengan Juni tahun 2016 dengan subjek sejumlah 20 anak dengan CP. Setelah mendapatkan perlakuan dan data terkumpul, dilakukan uji terhadap hipotesis yang kemudian diperoleh hasil sebagai berikut:

Tabel 1. Hasil Uji Mann-Withney Terhadap Kemampuan Terlentang dan Tengkurap

\begin{tabular}{ccccc}
\hline $\begin{array}{c}\text { Mann-Withney } \\
U\end{array}$ & Wilcoxon $W$ & $Z$ & $\begin{array}{c}\text { Asymp. Sig. } \\
\text { (2-tailed) }\end{array}$ & Keterangan \\
\hline 40.000 & 95.000 & -1.451 & .147 & $\begin{array}{c}\text { Tidak terdapat } \\
\text { perbedaan }\end{array}$ \\
\hline
\end{tabular}

Tabel 2. Hasil Uji Mann-Withney terhadap Kemampuan Duduk

\begin{tabular}{ccccc}
\hline $\begin{array}{c}\text { Mann-Withney } \\
U\end{array}$ & Wilcoxon $W$ & $Z$ & $\begin{array}{c}\text { Asymp. Sig. } \\
(2-\text { tailed })\end{array}$ & Keterangan \\
\hline 6.500 & 61.500 & -3.513 & .000 & $\begin{array}{c}\text { Terdapat } \\
\text { perbedaan }\end{array}$ \\
\hline
\end{tabular}

Tabel 3. Hasil Uji Mann-Withney terhadap Kemampuan Merangkak dan Berdiri dengan

\begin{tabular}{ccccc} 
Mann-Withney & Wilcoxon $W$ & Z & $\begin{array}{c}\text { Asymp. Sig. } \\
(2 \text {-tailed })\end{array}$ & Keterangan \\
\hline 1.000 & 56.000 & -4.026 & .000 & $\begin{array}{c}\text { Terdapat } \\
\text { perbedaan }\end{array}$ \\
\hline
\end{tabular}

Tabel 4. Hasil Uji Mann-Withney terhadap Kemampuan Berdiri

\begin{tabular}{ccccc}
\hline $\begin{array}{c}\text { Mann-Withney } \\
U\end{array}$ & Wilcoxon $W$ & Z & $\begin{array}{c}\text { Asymp. Sig. } \\
\text { (2-tailed) }\end{array}$ & Keterangan \\
\hline 1.000 & 56.000 & -3.941 & .000 & $\begin{array}{c}\text { Tidak terdapat } \\
\text { perbedaan }\end{array}$ \\
\hline
\end{tabular}

Tabel 5. Hasil Uji Mann-Withney terhadap Kemampuan Berjalan, Berlari dan Melompat 
Jumal Keperawatan dan Fisioterapi (JKF), e-ISSN 2655-0830

Vol. 2 No. 2 Edisi November 2019 - April 2020

https://ejournal.medistra.ac.id/index.php/JKF

Received: 27 April 2020 :: Accepted: 29 April 2020 :: Published: 30 April 2020

\begin{tabular}{ccccc}
\hline $\begin{array}{c}\text { Mann-Withney } \\
U\end{array}$ & Wilcoxon W & Z & $\begin{array}{c}\text { Asymp. Sig. } \\
(2-\text { tailed })\end{array}$ & Keterangan \\
\hline 5.000 & 60.000 & -3.724 & .000 & $\begin{array}{c}\text { Terdapat } \\
\text { perbedaan }\end{array}$ \\
\hline
\end{tabular}

Tabel 6. Hasil Uji Mann-Withney terhadap Kemampuan Motorik Fungsional

\begin{tabular}{ccccc}
\hline $\begin{array}{c}\text { Mann-Withney } \\
U\end{array}$ & Wilcoxon $W$ & $Z$ & $\begin{array}{c}\text { Asymp. Sig. } \\
\text { (2-tailed) }\end{array}$ & Keterangan \\
\hline 1.000 & 56.000 & -3.705 & .000 & $\begin{array}{c}\text { Terdapat } \\
\text { perbedaan }\end{array}$ \\
\hline
\end{tabular}

Berdasarkan tabel 1 , hasil $u j i$ Mann-Withney terhadap kemampuan motorik fungsional anak dengan $\mathrm{CP}$ pada dimensi terlentang dan tengkurap berdasarkan pemeriksaan GMFM setelah perlakuan menunjukkan nilai probabilitas $(\mathrm{sig})>0,05 \quad(0.147>0.05)$ yang berarti bahwa secara garis besar tidak terdapat perbedaan hasil terapi antara kelompok yang mendapatkan latihan NDT dengan kelompok yang mendapatkan latihan akuatik.

Berdasarkan tabel 2, hasil uji Mann-Withney terhadap kemampuan motorik fungsional anak dengan $\mathrm{CP}$ pada dimensi duduk berdasarkan pemeriksaan GMFM setelah perlakuan menunjukkan nilai probabilitas $(\mathrm{sig})<0,05(0.000<0.05)$ yang berarti bahwa secara garis besar terdapat perbedaan yang cukup signifikan dari hasil terapi antara kelompok yang mendapatkan latihan NDT dengan kelompok yang mendapatkan latihan akuatik.

Berdasarkan tabel 3, hasil uji Mann-Withney terhadap kemampuan motorik fungsional anak dengan $\mathrm{CP}$ pada dimensi merangkak dan berdiri dengan lutut berdasarkan pemeriksaan GMFM setelah perlakuan menunjukkan nilai probabilitas (sig) $<0,05$ $(0.000<0.05)$ yang berarti bahwa secara garis besar terdapat perbedaan yang cukup signifikan dari hasil terapi antara kelompok yang mendapatkan latihan NDT dengan kelompok yang mendapatkan latihan akuatik.

Berdasarkan tabel 4, hasil uji Mann-Withney terhadap kemampuan motorik fungsional anak dengan $\mathrm{CP}$ pada dimensi berdiri berdasarkan pemeriksaan GMFM setelah perlakuan menunjukkan nilai probabilitas $(\mathrm{sig})<0,05(0.000<0.05)$ yang berarti bahwa secara garis besar terdapat perbedaan yang cukup signifikan dari hasil terapi antara kelompok yang mendapatkan latihan NDT dengan kelompok yang mendapatkan latihan akuatik.

Berdasarkan tabel 5, hasil uji Mann-Withney terhadap kemampuang motorik fungsional anak dengan $\mathrm{CP}$ pada dimensi berjalan, berlari dan melompat berdasarkan pemeriksaan GMFM setelah perlakuan menunjukkan nilai probabilitas $(\mathrm{sig})<0,05$ $(0.000<0.05)$ yang berarti bahwa secara garis besar terdapat perbedaan yang cukup signifikan dari hasil terapi antara kelompok yang mendapatkan latihan NDT dengan kelompok yang mendapatkan latihan akuatik.

Berdasarkan tabel 6, hasil uji Mann-Withney terhadap kemampuan motorik fungsional anak dengan $\mathrm{CP}$ berdasarkan pemeriksaan GMFM secara keseluruhan setelah perlakuan menunjukkan nilai probabilitas $(\mathrm{sig})<0,05(0.000<0.05)$ yang berarti bahwa secara garis besar terdapat perbedaan yang cukup signifikan dari hasil terapi antara kelompok yang mendapatkan latihan NDT dengan kelompok yang mendapatkan latihan akuatik.

Penelitian Gorter dan Currie (2011) membuktikan tentang keamanan dan efektivitas latihan akuatik pada anak-anak dan remaja dengan CP terbatas.

Penelitian Dimitrijević et al. (2012) menerangkan bahwa terdapat efek signifikan mengikuti intervensi air 6 minggu pada fungsi motorik kasar anak-anak dengan CP. 
Studi eksplorasi yang dilakukan oleh Lai et al. (2015) menegaskan bahwa Terapi akuatik pada pediatri menghasilkan manfaat pada fungsi motorik dan aktivitas fisik, terutama untuk anak-anak dengan GMFM level II dan tipe spastik diplegia.

Menururt penelitian Arshad, Imran, Munir, Akram, \& Hameed (2018), teknik bobath atau neuro developmental technique's (NDT) dapat mengurangi spastisitas. Teknik bobath pada pembelajaran motorik kasar sangat efektif dan memang memainkan peran penting dalam CP. Ini meningkatkan tonus otot, refleks dan pola reaksi dan gerakan.

Pada penelitian Labaf et al. (2015), disimpulkan bahwa NDT dapat meningkatkan fungsional dari motorik kasar pada anak-anak dengan $\mathrm{CP}$ dalam empat dimensi pada GMFM. Peningkatan secara signifikan terdapat pada dimensi terlentang dan tengkurap, duduk, merangkak dan berlutut, dan berdiri. Namun, berjalan, berlari, dan melompat tidak membaik secara signifikan.

Pada penanganan anak penyandang $\mathrm{CP}$, metode NDT memberikan perbaikan langsung pada reaksi equilibrium dan righting yang mana telah diuraikan di atas bahwa kedua reaksi tersebut yang akan berpengaruh pada mekanisme refleks postural normal yang nantinya menjadi pendukung utama pada gerakan normal dalam kemampuan fungsional normal. Berdasarkan penelitian yang dilakukan oleh Ezema et al. (2014), menyimpulkan bahwa penelitian tersebut membuktikan bahwa metode NDT yang dilakukan oleh fisioterapi adalah modalitas terapi yang efektif untuk rehabilitasi CP. Disarankan penanganan dengan NDT pada penyandang $\mathrm{CP}$ dilakukan sesuai durasi yang tepat dan sedini mungkin untuk pemulihan yang lebih baik.

\section{KESIMPULAN}

Berdasarkan pengolahan data hasil penelitian, dari total 20 anak CP yang diteliti di WKCP berdasarkan hasil pemeriksaan dengan GMFM secara keseluruhan dapat disimpulkan bahwa latihan akuatik lebih berpengaruh terhadap perkembangan kemampuan motorik fungsional anak dengan $\mathrm{CP}$ dibandingkan dengan latihan NDT.

\section{DAFTAR PUSTAKA}

Arshad, N., Imran, M., Munir, Z., Akram, S., \& Hameed, A. A. (2018). SPASTIC CEREBRAL PALSY. The Professional Medical Journal.

https://doi.org/10.29309/tpmj/18. 4614.

Chiquoine, J., McCauley, L., \& Van Dyke, J. B. (2018). Aquatic Therapy. In Canine Sports Medicine and Rehabilitation: Second Edition. https://doi.org/10.1002/97811193 80627.

Dimitrijević, L., Aleksandrović, M., Madić, D., Okičić, T., Radovanović, D., \& Daly, D. (2012). The effect of aquatic intervention on the gross motor function and aquatic skills in children with cerebral palsy. Journal of Human Kinetics, 32(1), 167-174. https://doi.org/10.2478/v1007801 2-0033-5.

Ezema, C., Lamina, S., Nkama, R., Ezugwu, U., Amaeze, A., \& Nwankwo, M. (2014). Effect of neuro-developmental therapy (NDT) on disability level of subjects with cerebral palsy receiving physiotherapy at the University of Nigeria Teaching Hospital, Enugu, Nigeria. Nigerian Journal of Paediatrics, 41(2), 116. https://doi.

org/10.4314/njp.v41i2.7.

Gorter, J. W., \& Currie, S. J. (2011). Aquatic Exercise Programs for Children and Adolescents with Cerebral Palsy: What Do We Know and Where Do We Go? International Journal of Pediatrics, 2011, 1-7. https://doi.org/10.1155/2011/712 165.

Graham, H. K., Rosenbaum, P., Paneth, N., Dan, B., Lin, J. P., Damiano, 
Di. L., Lieber, R. L. (2016). Cerebral palsy. Nature Reviews Disease Primers.

https://doi.org/10.1038/ nrdp. 2015.82.

Harvey, A. R. (2017). The Gross Motor Function Measure (GMFM). Journal of Physiotherapy. https://doi.org/ 10.1016/j.jphys.2017.05.007.

Kenyon, L. K. (2014). Gross Motor Function Measure (GMFM-66 and GMFM-88) Users' Manual,. Physical \& Occupational Therapy In Pediatrics.

https://doi.org/10.3109/

01942638.2014 .931744$.

Kerem, M. (2011). Physiotherapy for Children with Cerebral Palsy. Epilepsy in Children - Clinical and Social Aspects. https://doi.org/10. 5772/20321.

Labaf, S., Shamsoddini, A., Taghi Hollisaz, M., Sobhani, V., \& Shakibaee, A. (2015). Effects of neurodevelopmental therapy on gross motor function in children with cerebral palsy. Iranian Journal of Child Neurology. https://doi.org/

10.22037/ijcn.v9i2.6165.

Lai, C. J., Liu, W. Y., Yang, T. F., Chen, C. L., Wu, C. Y., \& Chan, R. C. (2015). Pediatric aquatic therapy on motor function and enjoyment in children diagnosed with cerebral palsy of various motor severities. Journal of Child Neurology. https://doi.org/10.1177/08830738 14535491.

MacLennan, A. H., Thompson, S. C., \& Gecz, J. (2015). Cerebral palsy: Causes, pathways, and the role of genetic variants. American Journal of Obstetrics and Gynecology. https://doi.org/10.1016/j.ajog.201 5.05.034.

Marret, S., Vanhulle, C., \& Laquerriere, A. (2013). Pathophysiology of cerebral palsy. Handbook of Clinical Neurology, 111, 169-176. https://doi.org/10.1016/B9780444 -52891-9.00016-6.

McIntyre, S., Taitz, D., Keogh, J., Goldsmith, S., Badawi, N., \& Blair, E. (2013). A systematic review of risk factors for cerebral palsy in children born at term in developed countries. Developmental Medicine and Child Neurology. https://doi.org /10.1111/dmcn.12017.

Morgan, P., \& McGinley, J. L. (2018). Cerebral palsy. In Handbook of Clinical Neurology. https://doi.org/ 10.1016/B978-0-444639165.0002 0-3.

Roostaei, M., Baharlouei, H., Azadi, H., \& Fragala-Pinkham, M. A. (2017). Effects of Aquatic Intervention on Gross Motor Skills in Children with Cerebral Palsy: A Systematic Review. Physical and Occupational Therapy in Pediatrics. https://doi. org/10.1080/01942638.2016.1247 938.

Selina, H., Priambodo, W., \& Sakundarno, M. (2013). Gangguna Tidur Pada Anak Palsi Serebral. Medica Hospitalia: Journal of Clinical Medicine. https://doi.org/ 10.36408/mhjcm.v1i2.54.

Shira Sender, J. (2019). Cerebral Palsy: A Complete Guide for Caregiving. Journal of Consumer Health on the Internet.https://doi.org/10.1080/1 5398285.2019.1582252.

Stavsky, M., Mor, O., Mastrolia, S. A., Greenbaum, S., Than, N. G., \& Erez, O. (2017). Cerebral palsytrends in epidemiology and recent development in prenatal mechanisms of disease, treatment, and prevention. Frontiers in Pediatrics.

https://doi.org/10.3389/ fped.2017.00021.

Vitrikas, K., Dalton, H., \& Breish, D. (2020). Cerebral palsy: An overview. American Family Physician. 